\title{
Definition of the PRofession of midWife. Commentary on Article 5 Section 1a of the Act of 15 July 2011 ON THE PROFESSIONS OF NURSE AND MIDWIFE
}

\author{
Dorota Karkowska ${ }^{1 \mathrm{~A}, \mathrm{~B}, \mathrm{C}, \mathrm{D}, \mathrm{E}, \mathrm{F}}$, Tomasz Adam Karkowski $\mathrm{i}^{1,2 \mathrm{~A}, \mathrm{~B}, \mathrm{D}, \mathrm{F}}$
}

IInstitute of Nursing and Midwifery, Faculty of Health Sciences, Jagiellonian University Medical College, Krakow, Poland

${ }^{2}$ Department of Logistics and Innovations, The Faculty of Economics and Sociology, University of Lodz, Poland

Authors' contribution:

A. Study design/planning • B. Data collection/entry • C. Data analysis/statistics • D. Data interpretation $\bullet$ E. Preparation of manuscript $\bullet$ F. Literature analysis/search $\bullet$ G. Funds collection

\author{
Address for correspondence: \\ Dorota Karkowska \\ Institute of Nursing and Midwifery \\ Faculty of Health Sciences \\ Jagiellonian University Medical College \\ 25 Kopernika St., 31-501 Krakow, Poland \\ e-mail: dorota.karkowska@uj.edu.pl \\ SUBMITTED: 01.12 .2020 \\ ACCEPTED: 13.01.2021 \\ DOI: https://doi.org/10.5114/ppiel.2020.103533
}

\begin{abstract}
The legislator extended the substantive scope of the definition of the profession of midwife, using a simple legislative technique, i.e. copied the content of Article 4, Section 1 from point 1 to point 6 of the Act on the professions of nurse and midwife that contain the definition of the profession of nurse to the newly created Article 5 Section $1 \mathrm{a}$ of the Act. The literal meaning of this provision suggests that a person having the right to practice the profession of midwife in the event of an epidemic threat or state of an epidemic may perform activities appropriate for the profession of a nurse, although they are still to have the professional title of "midwife". If this was the legislator's intended goal, it is absolutely erroneous and inconsistent with the historical, systemic, purposeful, and functional interpretation, but also with the jurisprudence and legal doctrine, and would prove the legislator's irrationality. The law obliges employers and principals to employ medical professionals in accordance with their professional qualifications and health. Moreover, the employment of midwives in positions not corresponding to their professional qualifications and skills exposes medical entities to suffer legal liability in the future. Provision of specific health services without having the required license to practice is punishable by a fine, and if the person does so in order to gain financial benefits or is misleading as to having such a right, they are subject to a fine, restriction of liberty, or imprisonment of up to a year.
\end{abstract}

Key words: midwife, employment, nurse, COVID-19, epidemic threat.

The subject of the commentary is to discuss the information that some managers of medical entities employ midwives at the positions assigned to nurses and require them to perform the same range of professional activities as nurses.

The legal basis for such decisions is Section 1a of Article 5 of the Act of 15 July 2011 on the professions of nurse and midwife (hereinafter referred to as the Nurse and Midwife Act) [1], as interpreted with the relation to Article 4 Section 1 thereof. This provision was introduced in Article 13 of the Act of 14 August 2020 on amending certain acts to ensure the functioning of the healthcare system in connection with the COVID-19 epidemic and after it will have ceased (Journal of Laws of 2020) [2], as follows:

Article 5 Section $1 a$ of the Act on the professions of nurse and midwife states [1]: "In the event of announcing an epidemic threat or a state of an epidemic, the profession of a midwife may also include providing patients with health services in the scope of: 1) recognising health conditions and needs, 2) identifying nursing problems, 3) planning and providing nursing care, 4) independent provision of preventive, diagnostic, therapeutic, and rehabilitation services to a certain extent, 5) execution of medical orders in the process of diagnosis, treatment, and rehabilitation, 6) health education and health promotion - in accordance with the possessed qualifications and professional skills."

Also, the present commentary is based on the previous legal commentary prepared by the author for the Supreme Council of Nurses and Midwifes in Warsaw in September 2020 [3].

\section{COMMENTARY}

When interpreting Section 1a of Article 5 of the Nurse and Midwife Act [1] it is important to decide whether a person working as a midwife can legally provide health services to the same extent as a nurse. 
The power to provide health services in the scope specified in Article 4 Section 1, Article 5 Section 1, Article 6, and Article 15a of the Nurse and Midwife Act [1] and detailed in the executive acts issued for these provisions is granted by obtaining the right to practice a medical profession: the right to practice the profession of a nurse (Article 28 of the Nurse and Midwife Act) [1] or the right to practice the profession of a midwife (Article 31 of the Nurse and Midwife Act) [1], respectively. One of the four prerequisites is the submission of a nursing school diploma for those who want to work as a nurse (Article 52 of the Nurse and Midwife Act) [1] or the submission of a midwife school diploma for those who want to practice as a midwife (Article 53 of the Nurse and Midwife Act) [1]. The midwife school diploma, although it confirms the acquisition of appropriate theoretical knowledge and practical skills in the scope of performing certain nursing activities, is not a document on the basis of which the midwife obtained the right to perform medical activities in the field of nursing in accordance with the training system in nursing schools. The point is that the completion of a training intended only for midwives could not give the midwife greater powers in the field of nursing than those related to caring for a woman and a child under 8 weeks of age (Article 5 Section 1 of the Nurse and Midwife Act and the executive acts related thereof) [1].

The provision of Section 1a of Article 5 of the Nurse and Midwife Act [1] stating that during an epidemic threat or a state of epidemic the profession of a midwife may also involve providing patients with health services in the scope of: 1) recognising health conditions and needs, 2) identifying nursing problems, 3) planning and providing nursing care, 4) independent provision of preventive, diagnostic, therapeutic, and rehabilitation services to a certain extent, 5) execution of medical orders in the process of diagnosis, treatment, and rehabilitation, 6) health education and health promotion does not turn a midwife into a nurse during the time of an epidemic. The abovementioned provision is only a confirmation of what the persons working as midwives had been and still are entitled to in accordance with their professional qualifications and skills acquired in the pre-graduate and postgraduate education system. In my opinion, a literal copying of Section 1 of Article 4 of the Nurse and Midwife Act to Section 1a of Article 15 [1] does not change anything in the current legal status. The interpretation that treats midwives as nurses "interchangeably" is absolutely erroneous and contrary to the historical, systemic, purposeful, and functional interpretation.

If we assume that it is enough to change the provision so that persons practicing midwifery can provide health services that fall within the scope of the nursing profession, it can also be admitted, a contrario, that it is enough to change the content of Article 4 of the Nurse and Midwife Act [1] by adding Section 1a to it, as interpreted in Section 1 of Article 5 of the Nurse and Midwife Act [1], so that nurses can acquire professional qualifications in the scope of midwifery. Such an approach is difficult to consider as correct, since it disregards the statutory differentiation of the aforementioned professions of nurses and midwives, and does not notice that the significant differences in the course of their education mean that the midwife does not have the knowledge and skills necessary to conduct an effective and safe nursing process for patients in all of the diseases. In the case of a midwife, the education system focuses on their ability to care for a woman during pregnancy, childbirth, puerperium, and the entire period of her life related to female diseases and care for a newborn baby (Article 15 Section 1 of the Nurse and Midwife Act [1]).

However, the remarks concerning the overlapping competences of a nurse and a midwife in the provision of health services are not completely without significance. Nevertheless, one should bear in mind that when a midwife can support the health care system in the fight against an epidemic, without being prepared to care for infectious patients, in accordance with the content of Article 12 Section 1 of the Nurse and Midwife Act [1]: A nurse and a midwife are obliged, in accordance with their professional qualifications, to provide assistance in any case when a delay in providing it could result in a sudden health threat. On the other hand, I would like to emphasise once again that the mere fact of an overlap in some competences of a nurse and a midwife in providing health services does not make it justified to extend the scope of the definition of the profession of a midwife with elements appropriate for the definition of the profession of a nurse during the epidemic period. National consultants for obstetrics and nursing have also made clear statements on this matter.

It is worth recalling here that the competences of two other professions, i.e. doctor and dentist, also intersect in the scope of some professional activities (e.g. taking blood from a patient, performing injections, issuing prescriptions, etc.); however, these are still two separate medical professions that during an epidemic can be used to care for a patient suffering from COVID-19 on a general basis. At the same time, for the purposes of combating the effects of the epidemic, the legislator did not introduce changes in the definition of the profession of a dentist and did not extend its definition to match that of the profession of a doctor during the period of an epidemic. It was not done also due to the need to close dental offices.

And just as the medical community emphasises the differences in terms of professional qualifications and their powers between a doctor and a dentist, in light of the Act of 5 December 1996 on the profes- 
sions of doctor and dentist, Journal of Laws of 2020, item 514 [4], the differences in professional qualifications and the rights of the two independent medical professions of a nurse and a midwife must also be emphasised as clearly and strongly as according to the Act of 15 July 2011 on the professions of nurses and midwives [1].

Therefore, the arguments put forward by the Minister of Health that the changes introduced to the definition of the profession of midwife are only in the interest of this midwife community, so that they do not lose their jobs, are completely flawed.

\section{SUMMARY}

Summing up, I would like to point out that employing persons performing other medical professions as a nurse is associated with legal liability. In particular, it concerns criminal and civil liability. Provision of specific health services without having the required license to practice is punishable by a fine (Article 84 of the Nurse and Midwife Act) [1], and if the person does so in order to gain financial benefits or is misleading as to having such a right, they are subject to a fine, restriction of liberty, or imprisonment of up to a year (Article 85 of the Nurse and Midwife Act) [1]. On the other hand, anyone who employs a person without the required right to practice the profession to provide these healthcare services is subject to a fine or the penalty of restriction of liberty (Article 85 of the Nurse and Midwife Act) [1]. With regard to civil liability, persons suing medical entities may be both persons practicing medical professions who have suffered damage in connection with employment inconsistent with their professional qualifications, as well as patients or their heirs and other relatives, indicating that the damage suffered by the patient is a consequence of granting them health service contrary to the indications of current medical knowledge, due to the fact that a person who performed it does not have the required professional qualifications and skills.

\section{List of legal acts}

1. Act of 15 July 2011 on the professions of nurse and midwife (Journal of Laws of 2020, item 562 as amended).

2. Act of August 14, 2020 on amending certain acts to ensure the functioning of the healthcare system in connection with the COVID-19 epidemic and after it will have ceased (Journal of Laws of 2020).

3. Karkowska D. Commentary on Article 13 of the Act from 14 August 2020 on the modifications of some acts in order to guarantee the functioning of the healthcare in relation with the COVID-19 epidemic and after it, September 2020. Retrieved from: https://nipip.pl/czy-pielegniarka-mozezastapic-polozna-czy-polozna-moze-zastapic-pielegniarke/

4. Act of December 5, 1996 on the professions of doctor and dentist, Journal of Laws of 2020, item 514, as amended. 